Supplement of Biogeosciences, 17, 4871-4882, 2020

https://doi.org/10.5194/bg-17-4871-2020-supplement

(C) Author(s) 2020. This work is distributed under

the Creative Commons Attribution 4.0 License.

(c) (1)

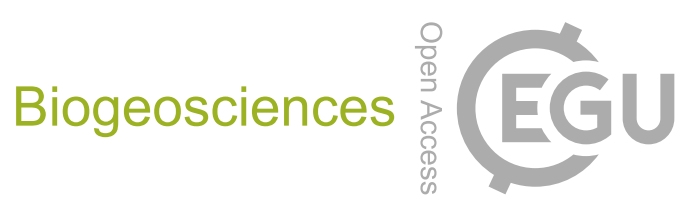

Supplement of

\title{
Alpine Holocene tree-ring dataset: age-related trends in the stable iso- topes of cellulose show species-specific patterns
}

Tito Arosio et al.

Correspondence to: Tito Arosio (tito.arosio@climate.unibe.ch)

The copyright of individual parts of the supplement might differ from the CC BY 4.0 License. 

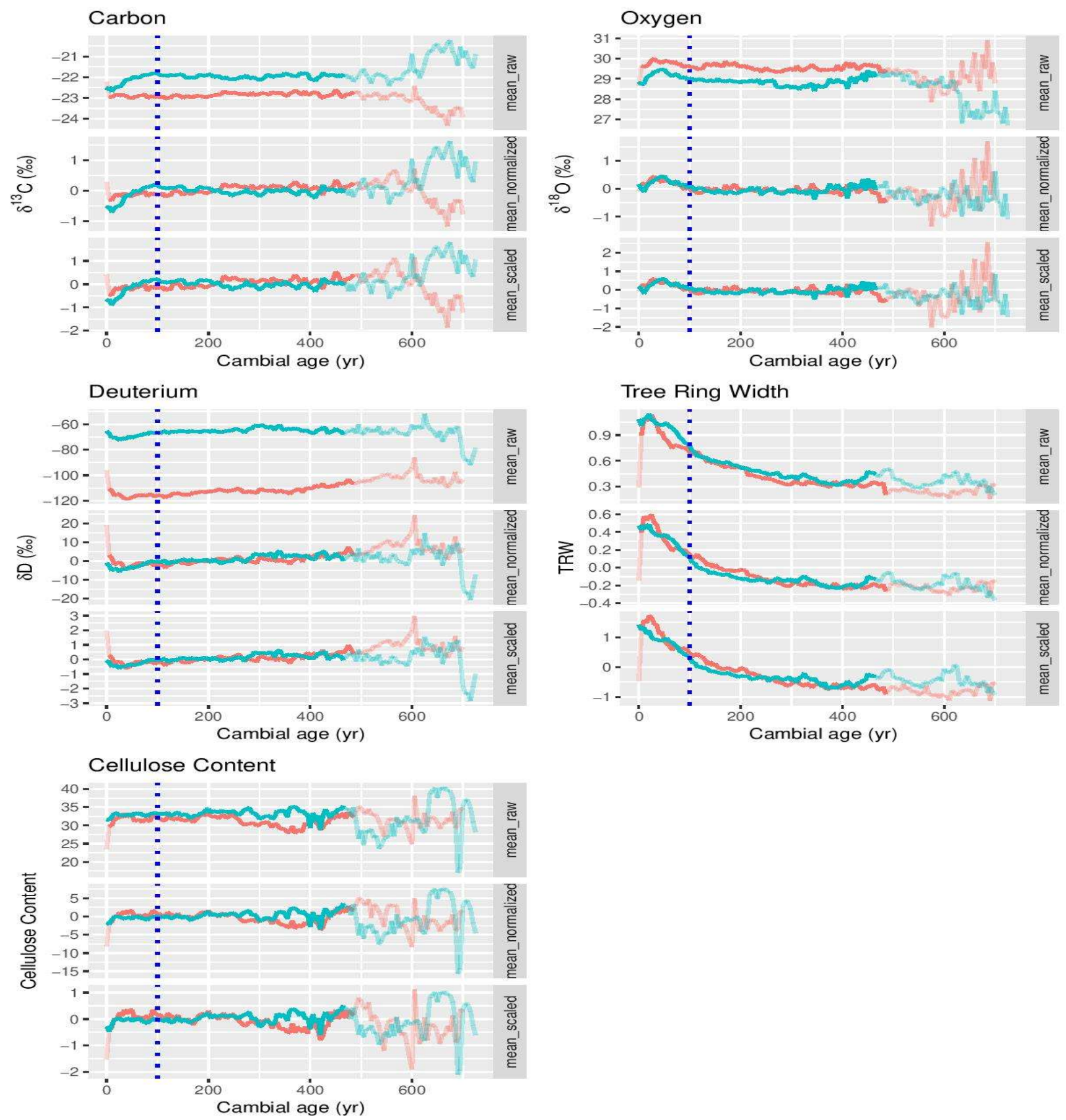

Supplement fig 1:

Comparison between raw, normalized and scaled (Z-score) values for each proxy. The darker lines represent replication of more or 5 equal than 10, the paler lines with less than 10, the vertical dotted blue line indicates $100 \mathrm{yr}$ 